University of Nebraska - Lincoln

DigitalCommons@University of Nebraska - Lincoln

Publications, Agencies and Staff of the U.S.

Department of Commerce

U.S. Department of Commerce

2011

\title{
A combined visual and acoustic estimate of 2008 abundance, and change in abundance since 1997, for the vaquita, Phocoena sinus
}

Tim Gerrodette

NOAA National Marine Fisheries Service, tim.gerrodette@noaa.gov

Barbara L. Taylor

NOAA National Marine Fisheries Service

René Swift

University of St. Andrews

Shannon Rankin

NOAA National Marine Fisheries Service

Armando M. Jaramillo-Legorreta

CICESE

See next page for additional authors

Follow this and additional works at: https://digitalcommons.unl.edu/usdeptcommercepub

Part of the Environmental Sciences Commons

Gerrodette, Tim; Taylor, Barbara L.; Swift, René; Rankin, Shannon; Jaramillo-Legorreta, Armando M.; and Rojas-Bracho, Lorenzo, "A combined visual and acoustic estimate of 2008 abundance, and change in abundance since 1997, for the vaquita, Phocoena sinus" (2011). Publications, Agencies and Staff of the U.S. Department of Commerce. 271.

https://digitalcommons.unl.edu/usdeptcommercepub/271

This Article is brought to you for free and open access by the U.S. Department of Commerce at DigitalCommons@University of Nebraska - Lincoln. It has been accepted for inclusion in Publications, Agencies and Staff of the U.S. Department of Commerce by an authorized administrator of DigitalCommons@University of Nebraska - Lincoln. 


\section{Authors}

Tim Gerrodette, Barbara L. Taylor, René Swift, Shannon Rankin, Armando M. Jaramillo-Legorreta, and Lorenzo Rojas-Bracho 


\title{
A combined visual and acoustic estimate of 2008 abundance, and change in abundance since 1997, for the vaquita, Phocoena sinus
}

\author{
TIM GERRODETTE \\ BARBARA L. TAYLOR \\ NOAA National Marine Fisheries Service, \\ Southwest Fisheries Science Center, \\ 3333 North Torrey Pines Court, \\ La Jolla, California 92037, U.S.A. \\ E-mail: tim.gerrodette@noaa.gov

\section{RENÉ SwIFT} \\ Sea Mammal Research Unit, \\ Scottish Oceans Institute, \\ University of St. Andrews, \\ St. Andrews, Fife KY16 8LB, United Kingdom

\section{SHANNON RANKIN} \\ NOAA National Marine Fisheries Service, \\ Southwest Fisheries Science Center, \\ 3333 North Torrey Pines Court, \\ La Jolla, California 92037, U.S.A.

\section{ARMANDo M. JARAMillo-LegorReta} \\ LORENZO ROJAS-BRACHO \\ Instituto Nacional de Ecología-SEMARNAT, \\ Coordinación de Investigación y Conservación de Mamíferos Marinos, CICESE, \\ Carretera Ensenada-Tijuana 3918 Zona Playitas, \\ Ensenada, BC 22860, Mexico
}

\begin{abstract}
A line-transect survey for the critically endangered vaquita, Phocoena sinus, was carried out in October-November 2008, in the northern Gulf of California, Mexico. Areas with deeper water were sampled visually from a large research vessel, while shallow water areas were covered by a sailboat towing an acoustic array. Total vaquita abundance in 2008 was estimated to be 245 animals (CV $=73 \%$, 95\% CI 68884). The 2008 estimate was $57 \%$ lower than the 1997 estimate, an average rate of decline of $7.6 \% / \mathrm{yr}$. Bayesian analyses found an $89 \%$ probability of decline in total population size during the $11 \mathrm{yr}$ period, and a $100 \%$ probability of decline in the central part of the range. Acoustic detections were assumed to represent porpoises with an average group size of 1.9, the same as visual sightings. Based on simultaneous visual and acoustic data in a calibration area, the probability of
\end{abstract}


detecting vaquitas acoustically on the trackline was estimated to be $0.41(\mathrm{CV}=$ 108\%). The Refuge Area for the Protection of the Vaquita, where gill net fishing is currently banned, contained approximately $50 \%$ of the population. While animals move in and out of the Refuge Area, on average half of the population remains exposed to bycatch in artisanal gill nets.

Key words: trend in abundance, endangered species, line transect, acoustic trackline detection probability, conservation, Phocoena sinus, vaquita abundance.

The vaquita (Phocoena sinus), or Gulf of California porpoise, was described as a species in 1958 (Norris and McFarland 1958). From the time of the initial description, its limited range (Brownell 1986, Silber 1990, Gerrodette et al. 1995) together with bycatch in fishing nets (Vidal 1995, D’Agrosa et al. 2000) prompted concerns for its conservation status. The first abundance estimate in 1997 based on the full range of the vaquita (Jaramillo-Legorreta et al. 1999) confirmed low total numbers of the species $(567,95 \%$ CI 177-1,073). This abundance estimate combined with the mortality estimate of 78 vaquitas (D'Agrosa et al. 2000) suggested a mortality rate of about $14 \%$ (78/567), which exceeded possible growth rates for porpoises. Based on these data and a subsequent increase in the number of artisanal fishing boats, Jaramillo-Legorreta et al. (2007) projected that the population might have declined to 150 vaquitas by 2007. Jaramillo-Legorreta et al. (2007) did not quantify the precision of this number, nor estimate the probability that the population had declined, given the large uncertainties about population size, amount of bycatch, and number of fishing vessels. The main point of the paper was that conservation action was urgently needed to prevent extinction.

In response to these indications of a decline, and in recognition of the insufficiency of conservation action preceding the extinction of the Chinese river dolphin or baiji (Lipotes vexillifer) (Turvey 2008), the Mexican government formed a recovery team in 2008, promulgated a conservation action plan (SEMARNAT 2008), and committed US $\$ 25$ million to conservation efforts. To maintain and justify such a large financial commitment, the government of Mexico wants rapid feedback on the efficacy of conservation actions. A joint US-Mexican research project in 2008 had the primary goal of developing new monitoring methods using autonomous acoustic devices, towed acoustic arrays or both (Rojas-Bracho et al. 2010). A secondary goal was to collect line-transect data for a current estimate of vaquita abundance. This paper reports on the line-transect effort and compares the resulting 2008 estimate of abundance to the previous range-wide estimate in 1997. The number of vaquitas and the fraction of the total population within two protected areas proposed in the vaquita conservation action plan are also estimated.

\section{METHODS}

\section{Study Area}

Transects were carried out between 16 October and 25 November 2008 in the northern Gulf of California, Mexico, where vaquitas are known to occur (Brownell 1986, Silber 1990, Gerrodette et al. 1995) (Fig. 1). In waters deeper than about 10 m, a large ship with sufficient height to detect vaquitas visually up to several kilometers from the ship has been successfully used on previous surveys (Barlow et al. 1997, 


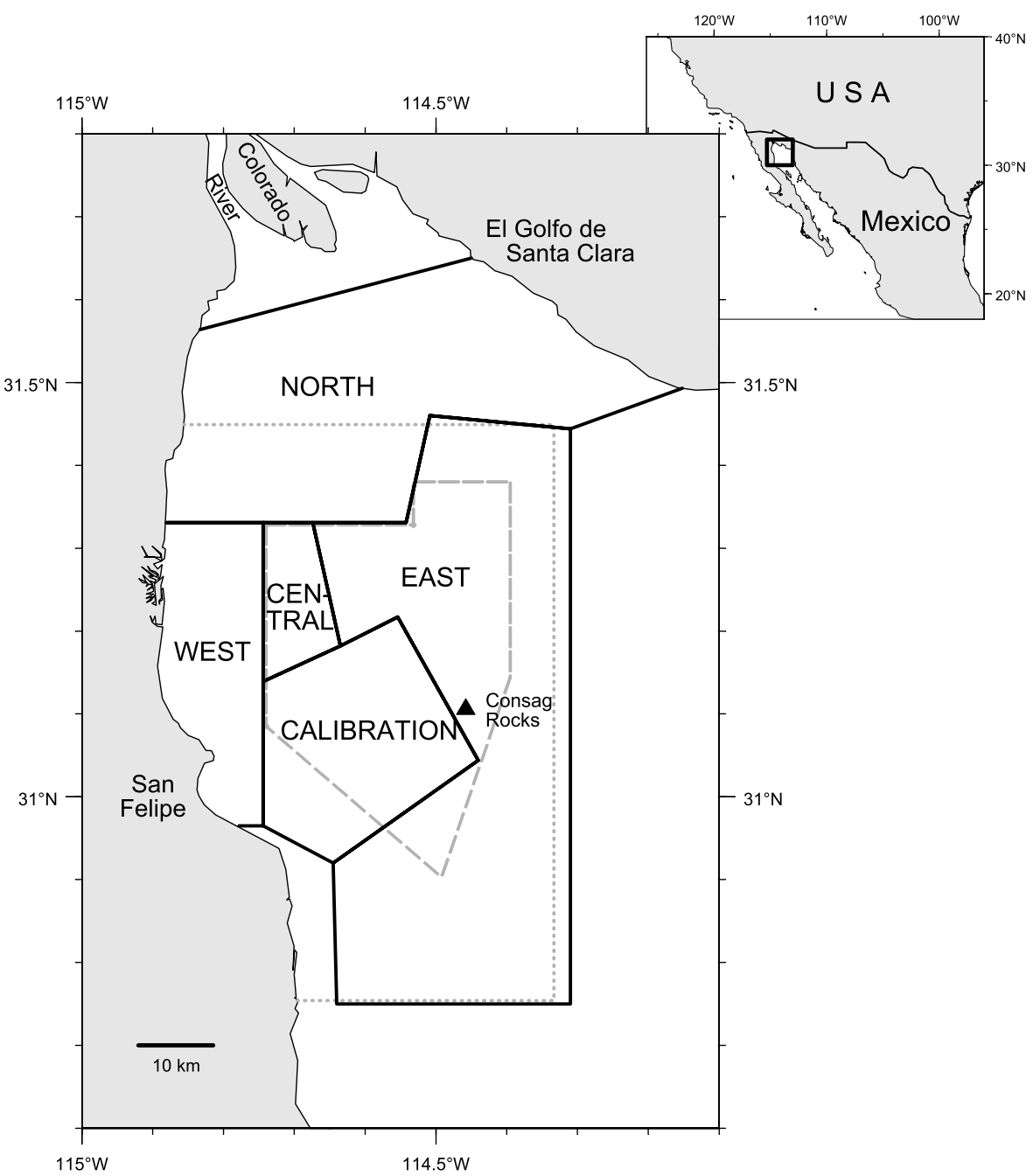

Figure 1. Study area in the northern Gulf of California, Mexico, with strata used for estimation of vaquita abundance in 2008. Two areas proposed for gill net fishing closure under the vaquita conservation action plan are shown with gray lines. The dashed gray line is the boundary of Option 1 (the Refuge Area for the Protection of the Vaquita), and the dotted gray line is the boundary of Option 2.

Jaramillo-Legorreta et al. 1999). In waters too shallow for a large vessel, vaquitas were detected acoustically with a hydrophone towed behind a sailboat.

\section{Visual Line-Transect Data}

Visual search effort was conducted from the David Starr Jordan, a $52 \mathrm{~m}$ oceanographic research vessel. A series of north-south transect lines $0.025^{\circ}$ of longitude 
$(2.38 \mathrm{~km})$ apart were laid out prior to the cruise, based on a random starting longitude. Line-transect methods were the same as a similar cruise in 1997 (Jaramillo-Legorreta et al. 1999), except that only a single team of observers was used during the 2008 cruise. Briefly, a team of three observers using pedestal-mounted 25X binoculars and a fourth observer using $7 \mathrm{X}$ hand-held binoculars searched for vaquitas as the ship traveled along the trackline at $6 \mathrm{kn}(11 \mathrm{~km} / \mathrm{h})$. All observers were experienced with field identification of vaquitas or harbor porpoises. When a marine mammal was sighted, angle and distance to the sighting were measured (Kinzey and Gerrodette 2001, 2003), and the fourth observer entered the data into a computer. Group size, Beaufort sea state, visibility, and other sighting conditions were recorded. The computer was connected to the ship's Global Positioning System to record the position of all data events. Occasionally the ship had to deviate from the planned trackline to avoid fishing nets or vessels, but otherwise the ship searched continuously in passing mode and did not approach sightings.

\section{Acoustic Line-Transect Data}

A stereo hydrophone array was towed $50 \mathrm{~m}$ behind a $24 \mathrm{ft}(7.3-\mathrm{m})$ Corsair trimaran, the Vaquita Express. The shallow draft of this sailboat allowed sampling in shallow water while minimizing disturbance. Following initial trials, transects were laid out to provide even spatial coverage and to sail at $4-5 \mathrm{kn}(7-9 \mathrm{~km} / \mathrm{h})$ given prevailing wind conditions in the upper Gulf of California. When vessel speed dropped below $3.5 \mathrm{kn}$ the sails were assisted by a $5 \mathrm{HP}$ four-stroke outboard engine.

Vaquitas produce distinctive narrowband (11-28 kHz), short (79-193 $\mu \mathrm{s})$, ultrasonic $(120-150 \mathrm{kHz})$ clicks with dominant frequencies ranging from 128 to $139 \mathrm{kHz}$, that are arranged into click trains consisting of 3-57 clicks with highly variable interclick intervals (0.019-0.144 s, Silber 1991). These characteristics allow reliable detection of vaquitas and separation from other sources of biological noise. Clicks are similar to those described for other members of the Phocoenidae, including the harbor porpoise (Phocoena phocoena), for which a reliable detector and classifier already exist (Gillespie and Chappell 2002).

The hydrophone array consisted of an oil-filled sensor section and two spherical elements separated by $25 \mathrm{~cm}$ coupled to preamplifiers. The combined hydrophone and preamplifier sensitivity was approximately $-161 \mathrm{~dB}$ re $1 \mathrm{~V} / \mu \mathrm{Pa}$, and the response was approximately flat from 2 to $200 \mathrm{kHz}$. Signals from each channel were routed through a buffer box to a National Instruments USB-6251 data acquisition board sampling at $480 \mathrm{kHz}$ and continuously recorded to a laptop computer using Logger 2000. The computer was connected to the ship's Global Positioning System and the ship's track was recorded at $10 \mathrm{~s}$ intervals. Environmental covariates such as sea state and wind speed were recorded every half hour. Further details of the survey equipment and protocols can be found in Rankin et al. (2009).

Field recordings were reprocessed using the Click detector module of PAMGuard ${ }^{1}$ using a standard trigger threshold set at $10 \mathrm{~dB}$, a digital high pass pre-filter at $40 \mathrm{kHz}$ (4-pole Butterworth) and a bandpass trigger filter set between 100 and $150 \mathrm{kHz}$ (4pole Butterworth). PAMGuard was set to output detected clicks in a RainbowClick

\footnotetext{
${ }^{1}$ Available at http://www.pamguard.org/home.shtml.
} 
click file (*.clk) format. ${ }^{2}$ Clicks were automatically classified using preconfigurable analysis options within RainbowClick. We used a standard set of click parameters tuned to detect and classify harbor porpoise clicks. The classifier compared energy in a test $(100-150 \mathrm{kHz})$ and control band $(20-80 \mathrm{kHz})$ and classified a click as vaquita if the minimum energy difference between the two bands exceeded $3 \mathrm{~dB}$. Additionally, the classifier searched for narrow band clicks with a peak frequency between 120 and $150 \mathrm{kHz}$ and classified the event as a vaquita if the estimated peak width was over $50 \%$ of the total energy and if the measured peak width was between 1 and $10 \mathrm{kHz}$. Click length or duration was also used to help discriminate between vaquita clicks and other sources of biological noise. The length of the waveform containing $50 \%$ of the total energy was measured, and if the returned value was $<2 \mathrm{~ms}$ the click was classified as vaquita. A single experienced analyst (RS) reviewed the click files. Definite vaquita events were click trains containing $\geq 5$ clicks matching Silber's (1991) description of vaquita clicks.

Perpendicular distances from the trackline were estimated from the crossing point of bearings from multiple clicks in each vaquita event. ${ }^{3}$ Covariates of sightings, computed for each $1 \mathrm{~km}$ segment of effort, included mean wind speed, mean sea state, mean vessel speed, mean underway (system) noise levels (dB) in the RainbowClick trigger band $(100-150 \mathrm{kHz})$, and the type of array.

\section{Estimation of Abundance}

The line-transect estimator of abundance was (Buckland et al. 2001)

$$
\hat{N}=\frac{n \hat{s} \mathrm{~A}}{2 \mathrm{WL} \hat{p} \hat{g}},
$$

where $\mathrm{A}$ was the area, $\mathrm{L}$ the distance searched along trackline (effort), $\mathrm{W}$ the strip width on each side of the trackline (truncation distance), $n$ the number of group detections, $\hat{s}$ the estimated population mean group size, $\hat{p}$ the estimated average of the detection function within distance $\mathrm{W}$ of the trackline, and $\hat{g}$ the estimated trackline detection probability $[g(0)]$.

Random variables ( $n, s, p$ and $g$ ) are indicated with italics. We used the delta method (Taylor Series approximation) to calculate the precision of estimates. Fixed parameters (A, L, and W) were assumed to be known without error and did not contribute to uncertainty. The squared coefficient of variation (CV) of $\hat{N}$, assuming independence of the random variables, was calculated as

$$
\mathrm{CV}^{2}(\hat{N})=\mathrm{CV}^{2}(n)+\mathrm{CV}^{2}(\hat{s})+\mathrm{CV}^{2}(\hat{p})+\mathrm{CV}^{2}(\hat{g}) .
$$

We calculated a $95 \%$ confidence interval, assuming a lognormal distribution on $\hat{N}$, as (Buckland et al. 2001)

\footnotetext{
${ }^{2}$ http://www.ifaw.org/ifaw_united_kingdom/join_campaigns/protecting_whales_around_the_world/ come_aboard_the_song_of_the_whale/download_cetacean_research_software/index.php.

${ }_{3}^{3}$ Personal communication from D. Gillespie, Sea Mammal Research Unit, Scottish Oceans Institute, University of St. Andrews, Fife, KY16 8LB, U.K., January 2009.
} 

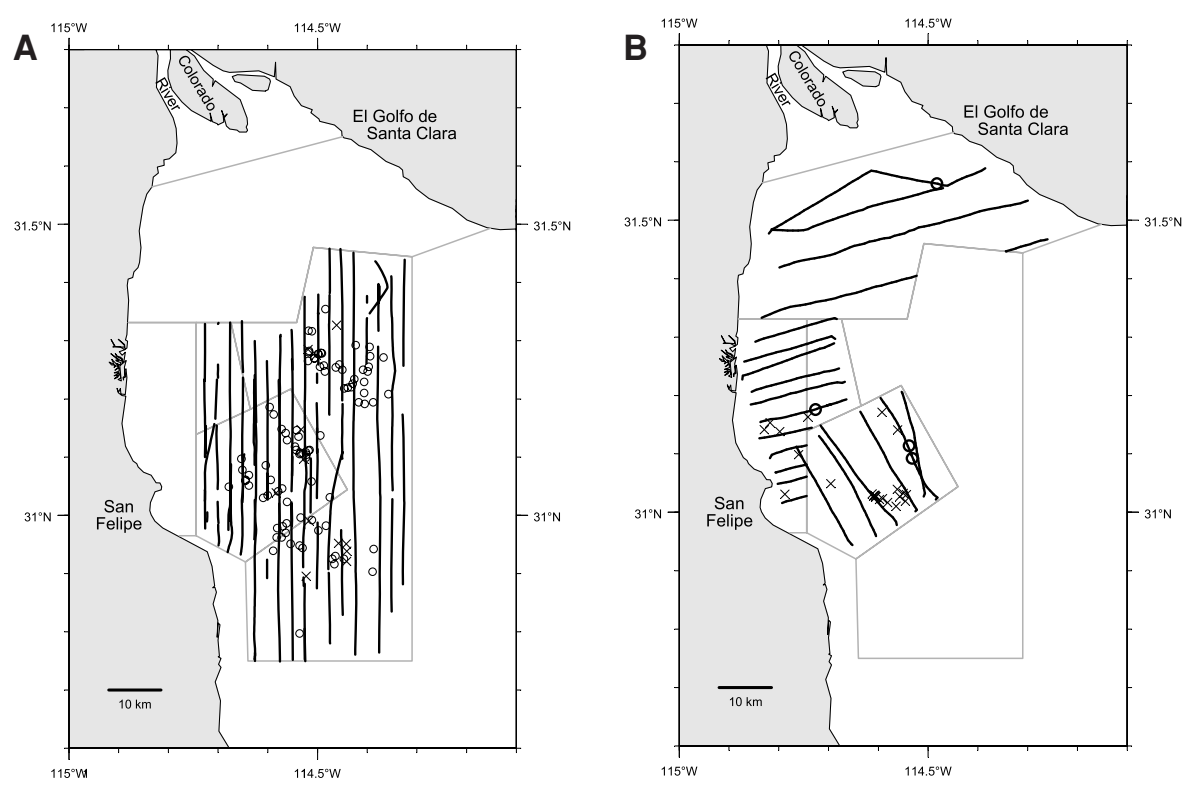

Figure 2. Transects (dark lines) and vaquita detections (circles) for (A) visual transects and (B) acoustic transects used for abundance estimation. Strata are shown as gray lines. X's show additional off-effort vaquita detections not used for abundance estimation.

$$
\left[\hat{N} / \exp \left(1.96 \sqrt{\ln \left(1+\mathrm{CV}^{2}(\hat{N})\right)}\right), \hat{N} * \exp \left(1.96 \sqrt{\ln \left(1+\mathrm{CV}^{2}(\hat{N})\right)}\right)\right]
$$

We used Distance 6 (Thomas et al. 2010) to estimate the average of the visual and acoustic detection functions, $\hat{p}_{v}$ and $\hat{p}_{a}$, and to compute the variance of the number of detections $n$ empirically from replicate transects (Fig. 2). Because the transects were designed to be random, we used the default variance estimator in Distance 6, the R2 estimator of Fewster et al. (2009). We considered half-normal and hazard-rate detection functions, with and without cosine and polynomial adjustment functions (Buckland et al. 2001). Beaufort sea state was considered as a covariate that might affect detection probability, and noise level was modeled as a covariate for the acoustic data. Visual detections were truncated at $\mathrm{W}_{v}=4 \mathrm{~km}$ and acoustic detections at $\mathrm{W}_{a}=$ $0.45 \mathrm{~km}$. Model-averaged estimates of $p_{v}$ and $p_{a}$ were based on Akaike weights

$$
w_{i}=\exp \left(-0.5 \Delta_{i}\right) / \sum_{j=1}^{k} \exp \left(-0.5 \Delta_{j}\right)
$$

where $\Delta_{i}$ was the difference in Akaike's Information Criterion (AIC) between the $i$ th of $k$ models and the model with the lowest AIC value (Anderson 2008).

For the visual data, estimation was based on search effort and sightings that occurred during on-effort periods in conditions of Beaufort sea state $\leq 2$. The probability of detecting vaquitas visually on the trackline from the flying bridge of the David Starr Jordan using a team of three observers with $25 \mathrm{X}$ binoculars was estimated to 
be $\hat{g}_{v}=0.571(\mathrm{CV}=32.7 \%)$, based on data from two independent observer teams (Jaramillo-Legorreta et al. 1999). For the acoustic data, estimation of abundance was based on effort and acoustic detections on transects, although estimation of the detection function included detections that occurred in transit to and from transects. The probability of detecting vaquitas acoustically on the trackline $\left(g_{a}\right)$ was estimated as described later.

\section{Stratification}

The study area was divided into five strata (Fig. 1). The deeper East stratum was surveyed visually by the David Starr Jordan, and the shallower North and West strata were surveyed acoustically by the Vaquita Express (Fig. 2). Both ships sampled the Calibration and Central strata. The Calibration stratum was an area within which the two vessels conducted simultaneous surveys for estimating the acoustic trackline detection probability as described below. Outside of this period of simultaneous surveys, the David Starr Jordan carried out additional transects within the Calibration area; effort, sightings and estimates from this survey effort are designated "Calibration2" in Tables 1 and 2. The Vaquita Express also had additional transects within the Calibration stratum, but these transects did not cover the whole stratum and were not used for abundance estimation. However, the perpendicular distance of one detection from these transects was included in the estimation of the acoustic detection function.

We estimated abundance from visual data in the East, Central, and Calibration strata and from acoustic data in the West, Central, Calibration, and North strata. We combined visual and acoustic data to produce a single estimate of density and abundance in each stratum (Appendix A). Mean group size of acoustic detections was assumed to be equal to mean group size of visual detections (see Results). We assumed average group size $s$, average detection function $p$ and trackline detection probability $g$ were the same for all strata.

The estimator of total abundance was the sum of the stratum estimators. The stratum estimators were not independent because they shared common terms. The variance of the total estimate was calculated with the delta method, factoring out common terms to account for covariance (Appendix B).

Table 1. Area, effort and number of vaquita detections, by stratum and data type, used in the estimation of vaquita abundance in 2008. Calibration 2 indicates visual effort and sightings in the Calibration stratum not simultaneous with acoustic effort.

\begin{tabular}{|c|c|c|c|c|c|}
\hline \multirow[b]{2}{*}{ Stratum } & \multirow[b]{2}{*}{ Area in $\mathrm{km}^{2}$} & \multicolumn{2}{|c|}{ Effort in $\mathrm{km}(\mathrm{L})$} & \multicolumn{2}{|c|}{$\begin{array}{c}\text { Number of } \\
\text { detections }(n)\end{array}$} \\
\hline & & Visual & Acoustic & Visual & Acoustic \\
\hline Calibration & 612.86 & 164.8 & 132.0 & 28 & 2 \\
\hline Calibration2 & 612.86 & 174.3 & - & 12 & - \\
\hline Central & 165.60 & 57.0 & 39.9 & 0 & 1 \\
\hline East & $1,959.72$ & 634.8 & - & 48 & - \\
\hline West & 473.51 & - & 106.5 & - & 0 \\
\hline North & $1,430.10$ & - & 170.5 & - & 1 \\
\hline Total & $4,641.79$ & $1,030.9$ & 448.9 & 88 & 4 \\
\hline
\end{tabular}


Table 2. Estimates of 2008 vaquita abundance $(\mathrm{N})$ and density $\left(\mathrm{D}\right.$, per $\left.\mathrm{km}^{2}\right)$, with measures of precision.

\begin{tabular}{lllrrrr}
\hline \hline Type & Stratum & \multicolumn{2}{c}{ Estimate } & CV(\%) & L95 & U95 \\
\hline Visual & Calibration & $\mathrm{N}$ & 80 & 40.3 & 38 & 172 \\
& Calibration2 & $\mathrm{N}$ & 33 & 47.2 & 14 & 78 \\
& East & $\mathrm{N}$ & 114 & 45.6 & 49 & 268 \\
& Central & $\mathrm{N}$ & 0 & - & - & - \\
Acoustic & Calibration & $\mathrm{N}$ & 80 & 147.5 & 10 & 659 \\
& Central & $\mathrm{N}$ & 36 & 141.6 & 5 & 280 \\
& West & $\mathrm{N}$ & 0 & - & - & - \\
& North & $\mathrm{N}$ & 72 & 141.8 & 9 & 567 \\
Combined & Calibration & $\mathrm{N}$ & 56 & 52.3 & 21 & 146 \\
& & $\mathrm{D}$ & 0.091 & 52,3 & 0.035 & 0.238 \\
& East & $\mathrm{N}$ & 114 & 45.6 & 49 & 268 \\
& & $\mathrm{D}$ & 0.058 & 45.6 & 0.025 & 0.137 \\
& Central & $\mathrm{N}$ & 3 & 138.1 & 1 & 20 \\
& & $\mathrm{D}$ & 0.016 & 138.1 & 0.002 & 0.120 \\
& West & $\mathrm{N}$ & 0 & - & - & - \\
& & $\mathrm{D}$ & 0 & - & - & - \\
& North & $\mathrm{N}$ & 72 & 141.8 & 9 & 567 \\
& & $\mathrm{D}$ & 0.051 & 141.8 & 0.006 & 0.397 \\
& & $\mathrm{~N}$ & 245 & 73.2 & 68 & 884 \\
& Optal & $\mathrm{N}$ & 121 & 38.2 & 59 & 250 \\
& Option 2 & $\mathrm{N}$ & 195 & 59.6 & 66 & 575 \\
\hline
\end{tabular}

Note: $\mathrm{CV}=$ coefficient of variation, L95 and U95 = lower and upper limits of the $95 \%$ lognormal confidence interval. Strata are shown in Fig. 1. Combined estimates are weighted averages of the stratified visual and acoustic estimates, and the total estimate is a sum of the combined estimates (see text for details). Acoustic estimates include the acoustic trackline detection probability $g_{a}$ estimated from simultaneous visual and acoustic surveys in the Calibration area; thus visual and acoustic estimates in the Calibration area were equal by design. Option 1 and Option 2 refer to vaquita protection areas proposed in the conservation action plan (see Fig. 1).

We also estimated abundance within two areas proposed in the vaquita conservation action plan (SEMARNAT 2008) as protected areas within which gill net fishing would be prohibited: Option 1 and Option 2 (Fig. 1). Option 1 is the existing Refuge Area for the Protection of the Vaquita. Abundance in the Refuge Area was estimated from visual sightings and effort within the Refuge Area, with all visual data used to estimate group size and detection function. Abundance in the Option 2 area was estimated as the sum of combined visual and acoustic estimates in the East, Central, Calibration, and West strata, and a fraction of the estimated abundance in the North stratum prorated by area.

\section{Acoustic Trackline Detection Probability}

We estimated acoustic trackline detection probability $g_{a}$ from simultaneous visual and acoustic surveys in the Calibration stratum from 17 to 24 October 2008. Using the line-transect abundance estimator (Eq. 1) and setting the visual and acoustic 
estimators to be equal,

$$
\frac{n_{v, \text { Cal }} \hat{s} \mathrm{~A}_{C a l}}{2 \mathrm{~W}_{v} \mathrm{~L}_{v, \text { Cal }} \hat{p}_{v} \hat{g}_{v}}=\frac{n_{a, C a l} \hat{s} \mathrm{~A}_{C a l}}{2 \mathrm{~W}_{a} \mathrm{~L}_{a, C a l} \hat{p}_{a} \hat{g}_{a}},
$$

where subscripts $v$ and $a$ refer to visual and acoustic data, and Cal refers to the Calibration stratum. Solving for $\hat{g}_{a}$,

$$
\hat{g}_{a}=\frac{n_{a, \text { Cal }} \mathrm{W}_{v} \mathrm{~L}_{v, \text { Cal }} \hat{p}_{v} \hat{g}_{v}}{n_{v, \text { Cal }} \mathrm{W}_{a} \mathrm{~L}_{a, \text { Cal }} \hat{p}_{a}},
$$

and, using the delta method,

$$
\mathrm{CV}^{2}\left(\hat{g}_{a}\right)=\mathrm{CV}^{2}\left(n_{a}, C_{a l}\right)+\mathrm{CV}^{2}\left(n_{v, C a l}\right)+\mathrm{CV}^{2}\left(\hat{g}_{v}\right)+\mathrm{CV}^{2}\left(\hat{p}_{v}\right)+\mathrm{CV}^{2}\left(\hat{p}_{a}\right) .
$$

\section{Comparison with 1997 Abundance}

We estimated the change in vaquita abundance between 1997 and 2008 in two ways, using Bayesian methods. First, we estimated the change in total abundance using the point estimates and their standard errors. Let $N_{1997}$ be vaquita abundance in 1997, and $d$ the difference in abundance between 1997 and 2008, so that abundance in $2008=N_{1997}+d$. Values of $d>0$ indicated an increase in abundance, while values of $d<0$ indicated a decrease. We assumed uniform priors for $N_{1997}$ and $d$. We also assumed that the 1997 and 2008 estimates were independent, although the visual parts of the total estimates in each year shared a common estimate of trackline detection probability. The joint likelihood was

$$
\operatorname{Lognormal}\left(N_{1997} ; 567,266\right) \cdot \operatorname{Lognormal}\left(N_{1997}+d ; 245,179\right) \text {, }
$$

where Lognormal $(x ; a, b)$ was the lognormal probability density of $x$ given mean $a$ and standard deviation $b, 567$ and 266 were the 1997 estimate and its SE, and 245 and 179 were the 2008 estimate and its SE (see Results). The marginal posterior distribution of $d$ was obtained by numerical integration of the joint posterior over $N_{1997}$.

Second, we estimated the change in abundance in the central area of vaquita distribution where $95 \%$ of sightings have occurred, with simultaneous estimation of all parameters. In 1997 and 2008, the same area (the Core Area defined in JaramilloLegorreta et al. 1999, and roughly the East and Calibration strata in Fig. 1) was surveyed by the same vessel (David Starr Jordan) using identical methods. The change in abundance within this area should therefore be a good indication of the trend of the population, assuming that there has been no shift in distribution. We used a simple form of a Bayesian line-transect analysis (Eguchi and Gerrodette 2009) to estimate the joint posterior distribution of the effective strip half-widths (ESWs), abundances and change in abundance. ESW and abundance were estimated for each year using vague priors and half-normal detection functions with no covariates. Mean group sizes (1.89 in $1997,1.86$ in 2008) were treated as known. The number of sightings was assumed to be binomially distributed (Eguchi and Gerrodette 2009). The informative prior for $g_{v}$ was a beta $(4,3)$ distribution, based on four matches of seven detections by 
two independent observer teams (Jaramillo-Legorreta et al. 1999). The parameter of interest was again $d$, the change in abundance in the central area over the 11-yr period, whose marginal posterior distribution was obtained by integrating the joint posterior distribution over the other four parameters. The analysis was carried out in R (R Development Core Team 2009) using direct computation of priors, likelihoods, and posteriors at regular intervals in a 5-dimensional space. Code is available from the first author on request.

\section{RESULTS}

Transects by both vessels achieved reasonably uniform coverage of the strata they sampled (Fig. 2). There was a total of 88 vaquita sightings within $4 \mathrm{~km}$ of the trackline during $1,030.9 \mathrm{~km}$ of effort in conditions of Beaufort $\leq 2$ (Table 1). The spatial distribution of sightings was clustered (Fig. 2). As a simple measure of this aggregation, the variances in the number of sightings per transect in the East and Calibration strata were each about five times the means.

There was a total of 29 acoustic detections with perpendicular distances $<450 \mathrm{~m}$. Only four of these detections, however, occurred on $448.9 \mathrm{~km}$ of transect effort in the strata (Table 1). Most acoustic detections occurred during transit to and from the planned transects (Fig. 2).

For the visual data, a half-normal detection function with Beaufort as a covariate had the lowest AIC (Fig. 3A). A half-normal function without a Beaufort covariate, a half-normal function with a Beaufort covariate and cosine adjustments, a half-normal function with cosine adjustments, and a hazard-rate function estimated slightly larger ESWs and had AIC differences of 1.52, 1.98, 3.52, and 4.52, respectively. The model-averaged estimate of the visual effective strip half-width was $\mathrm{ESW}_{v}=$

A

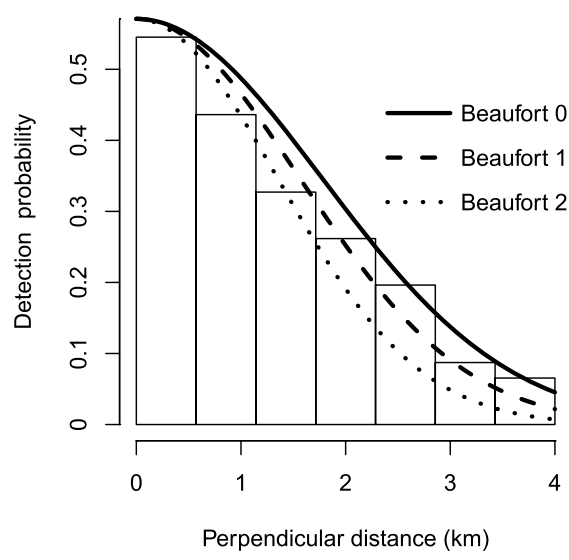

B

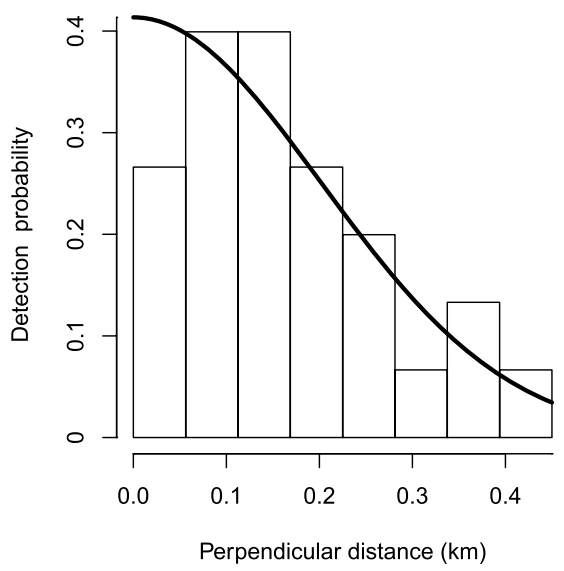

Figure 3. Half-normal detection functions and histogram of perpendicular distances for (A) 88 visual detections with Beaufort sea state as a covariate and (B) 29 acoustic detections. Plots show detection functions with lowest AIC, although abundance estimation was based on model-averaged detection functions. Detection probabilities include estimated trackline detection probabilities $g_{v}$ and $g_{a}$. 
$2.120 \mathrm{~km}\left(\hat{f}_{v}(0)=0.472 \mathrm{~km}^{-1}\right)$. Thus, $\hat{p}_{v}=\mathrm{ESWW}_{v} / \mathrm{W}_{v}=0.530$ with $\mathrm{CV}\left(\hat{p}_{v}\right)=$ $9.0 \%$.

For the acoustic data, a half-normal model with no covariates or adjustments had lowest AIC and fit the perpendicular distances of the 29 detections reasonably well (Fig. 3B). A hazard-rate function, a half-normal function with cosine adjustments and a hazard-rate function with polynomial adjusted estimated similar ESWs but had AIC differences of 1.29, 1.82 and 3.29, respectively. The model-averaged estimate of the acoustic effective strip half-width was $\mathrm{ESWW}_{a}=0.261 \mathrm{~km}\left(\hat{f}_{a}(0)=3.83 \mathrm{~km}^{-1}\right)$. Thus, $\hat{p}_{a}=\mathrm{ESSW}_{a} / \mathrm{W}_{a}=0.580$ with $\mathrm{CV}\left(\hat{p}_{a}\right)=21.9 \%$.

Group sizes of the 88 sightings ranged from 1 to 10 , with mean 1.86 and frequencies $32,42,0,11,0,1,0,1,0$, and 1 . Of the 29 acoustic detections, only one was a pair of click trains that could be interpreted as a pair of animals. If vaquita group sizes in areas surveyed acoustically were the same as in areas surveyed visually, then many of the single acoustic detections represented groups of animals. To estimate abundance, we assumed that group size of acoustic detections was the same as visual detections. There was no significant relation between visual group sizes and detection probability or distance from trackline, so the mean of observed group sizes was used as expected group size for abundance estimation. Thus, $\hat{s}=1.86$ with $\mathrm{CV}=5.1 \%$.

During the $8 \mathrm{~d}$ the two vessels conducted simultaneous surveys, there were 28 visual detections in $164.8 \mathrm{~km}$ of effort and 2 acoustic detections in $132.0 \mathrm{~km}$ of effort (Table 1). From Eq. (2), $g_{a}$ was estimated to be 0.413 with CV $=108 \%$.

Total 2008 vaquita abundance was estimated to be 245 , with $\mathrm{SE}=179, \mathrm{CV}=$ $73.2 \%$ and a $95 \%$ CI from 68 to 884 vaquitas (Table 2). Abundance by stratum ranged from 114 in the East to 0 in the West. Vaquita density was highest in the Calibration and East strata, with estimates of $0.091 \mathrm{~km}^{-2}$ and $0.058 \mathrm{~km}^{-2}$, respectively. Estimated density in the North stratum was nearly as high, but this estimate was highly uncertain, based on a single acoustic detection. The estimated numbers of vaquitas in the Calibration area for the visual and acoustic data were equal by design, because the acoustic estimate included a "calibration factor" estimated by setting the visual and acoustic estimates equal during the $8 \mathrm{~d}$ calibration effort (Appendix A). Based on all visual data, 56 vaquitas were estimated to be present in the Calibration stratum.

The estimates in the East and Calibration strata were based on the visual transect effort and had CVs of $46 \%$ and $52 \%$, respectively (Table 2). For both strata, over $95 \%$ of the variance in the density estimate was due to variance in encounter rate and trackline detection probability. Variance in encounter rate alone accounted for half of the variance in the East stratum and almost two-thirds of the variance in the Calibration stratum. There were no sightings in the Central stratum, despite good visual survey coverage. The acoustic estimate of abundance in the Central stratum was 36, based on a single detection. The combined estimate of three vaquitas in the Central stratum was heavily weighted by the visual estimate of no vaquitas, since the visual survey covered a much larger area. The estimate of abundance in the Central stratum was highly uncertain with a CV of $138 \%$. In the West stratum, there were no acoustic detections on the planned tracklines, so the estimate of abundance was zero. However, vaquitas were detected acoustically in the West stratum during transit (Fig. 2). In the North stratum, there were an estimated 72 vaquitas, based on a single acoustic detection. This estimate was also highly uncertain, with a CV of $142 \%$ and a $95 \%$ confidence interval from 9 to 567. 

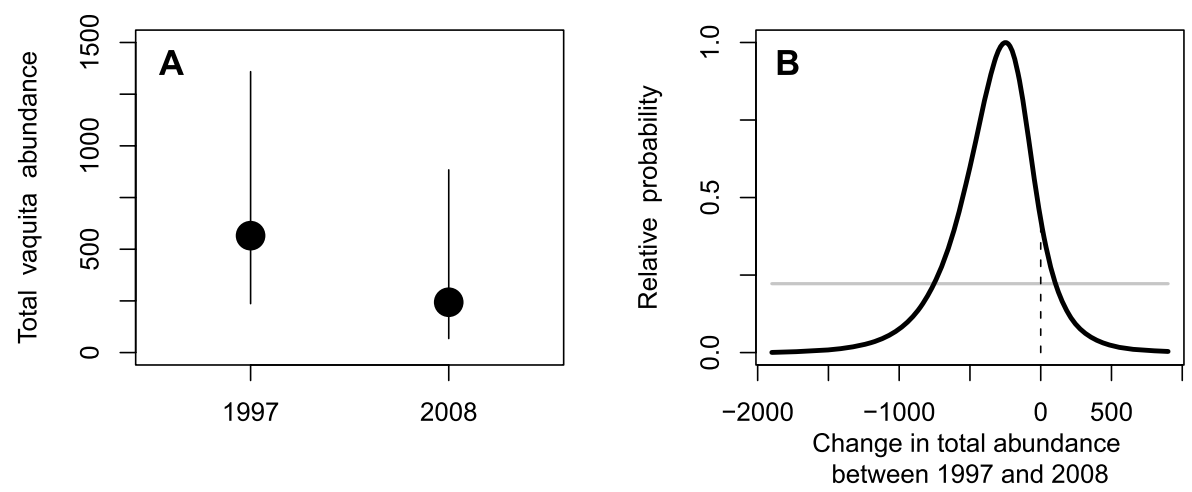

Figure 4. Comparison of total vaquita abundance in 1997 and 2008. (A) Point estimates with 95\% lognormal confidence intervals. (B) Marginal posterior distribution of change in total abundance between 1997 and 2008. Gray line is the prior distribution of change in abundance. Negative values indicate a smaller population in 2008. The dashed vertical line at 0 helps to visualize the cumulative probability that the vaquita population increased or decreased between 1997 and 2008 .

Within the area of Option 1 (the Refuge Area for the Protection of the Vaquita), we estimated 121 vaquitas (95\% CI 59-250, Table 2), based on 71 sightings in $568.9 \mathrm{~km}$ of effort. Therefore, approximately half $(121 / 245)$ of the vaquita population was within the Refuge Area. The Option 2 area included $31 \%$ of the area of the North stratum (Fig. 1). We estimated that 195 vaquitas (95\% CI 66-575), or about $80 \%$ of the total population, were inside the Option 2 area.

The 2008 estimate was 43\% (245/567) of the 1997 estimate, a decrease that would be produced by a $7.6 \%$ per year rate of decline over the $11 \mathrm{yr}$ period. Both estimates had large CIs, which included or nearly included the other point estimate (Fig. 4A). The posterior distribution of the change in total abundance between 1997 and 2008 had a mode of -248 , a mean of -322 , a median of -298 , and $88.6 \%$ of the probability mass $<0$ (Fig. $4 \mathrm{~B}$ ).

For the central area sampled with identical methods in 1997 and 2008, effort was $514 \mathrm{~km}$ in 1997 and $872 \mathrm{~km}$ in 2008, and the number of sightings was 88 in each year. The 2008 estimate was $41 \%$ of the 1997 estimate, based on the modes of 425 and 174 of the posterior distributions for 1997 and 2008, respectively (Fig. 5A). This 59\% decrease would be produced by a rate of decline of $8.1 \%$ per year. The posterior distribution of the change in abundance in the central area had a mode of -120 , a mean of -166 , a median of -154 , and $>99.999 \%$ of the probability mass $<0$ (Fig. 5B).

\section{DISCUSSION}

\section{Change in Vaquita Abundance Between 1997 and 2008}

The 2008 estimate of 245 vaquitas was less than half the 1997 estimate of 567 (Jaramillo-Legorreta et al. 1999). The two point estimates implied a rate of decline of $7.6 \%$ per year and a total decline of $57 \%$ over the $11 \mathrm{yr}$ period. The $95 \% \mathrm{CI}$ of the 2008 estimate from 68 to 884 vaquitas included the estimate of 150 based on a predicted trend from 1997 to 2007 (Jaramillo-Legorreta et al. 2007). 

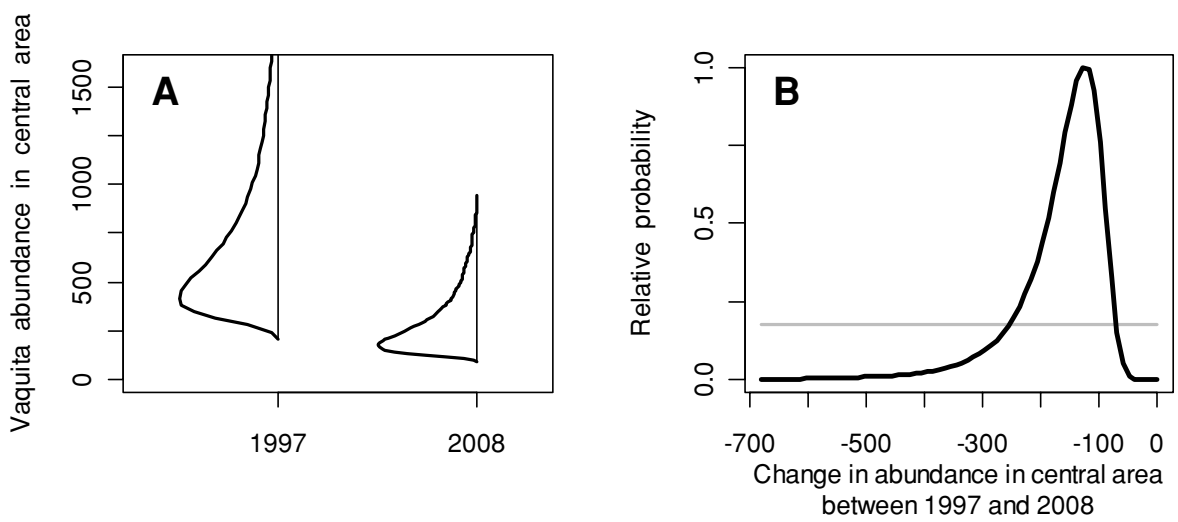

Figure 5. Comparison of vaquita abundance in a common central study area in 1997 and 2008. (A) Marginal posterior distributions of abundance for each year. (B) Marginal posterior distribution of change in abundance in the central area between 1997 and 2008. Gray line is the prior distribution of change in abundance. Negative values indicate a smaller population in 2008 .

The estimates of total abundance in 1997 and 2008 were both imprecise, with CVs $>50 \%$. Given low precision and wide overlap in confidence intervals (Fig. 4A), the two total estimates were not "significantly different" as measured by a null hypothesis significance test $(t=1.00, P \geq 0.31$ with two-tailed $\alpha=0.05$, Appendix C). The estimates from the central area were also not "significantly different" $(t=$ $0.97, P \geq 0.33$, Appendix $C$ ). However, significance tests have many difficulties in application and interpretation (Yoccoz 1991, Cohen 1994, Johnson 1999). Taylor and Gerrodette (1993) showed that such tests have poor ability to detect changes in abundance for the vaquita and other rare species. Equivalence tests for negligible trends (Dixon and Pechmann 2005) are more informative but do not avoid the convoluted logic of significance testing (Camp et al. 2008).

The result of a Bayesian analysis, on the other hand, is a simple and direct statement of the probability of a decline (or increase). We estimated an $89 \%$ probability of decline in total population size between 1997 and 2008 (Fig. 4B). In other words, it was $0.89 /(1-0.89) \cong 8$ times more probable that the total population decreased between 1997 and 2008 than that it increased. Based on the simultaneous estimation of all parameters in the central area of the vaquita's range, the probability of decline was $>99.999 \%$ (Fig. 5B). Thus it was virtually certain that the vaquita population was smaller in 2008 than in 1997 in the central area. The greater estimated probability of decline for the central area was due to the integrated analysis with simultaneous estimation of all parameters. These results indicating a decline in abundance were consistent with an estimated $85 \%$ probability of decline between 1997 and 2007 based on acoustic monitoring (Jaramillo-Legorreta 2008).

When monitoring to detect changes in abundance, the analysis should include factors that affect probability of detection (MacKenzie et al. 2002, Ver Hoef and Frost 2003, Royle 2004, Thomas et al. 2004). In many marine mammal studies, sighting rate is used as an index of abundance, which does not account for the effect of Beaufort sea state, behavior, or other factors that affect sighting rates and that might differ among occasions. In this study, for example, even though surveys were 
conducted only in excellent conditions (Beaufort $\leq 2$ ), vaquita sighting rates declined by only 41\%, while abundance declined by 59\%, between 1997 and 2008 in the central area. The difference was due to better sighting conditions in 2008-mean Beaufort sea state was 1.43 in 1997 and 0.93 in 2008. Line-transect analysis adjusted for the difference in sighting conditions between the $2 \mathrm{yr}$ by estimating a larger ESW in the better conditions- $1.81 \mathrm{~km}$ in $1997 v$ s. $2.12 \mathrm{~km}$ in 2008 . Had sighting rates alone been used to assess change in vaquita abundance, the decline would have been underestimated by $31 \%$ because the effect of better sighting conditions in 2008 would not have been accounted for.

The 2008 visual line-transect effort was unusually intense, and the results emphasized how difficult it is to obtain a precise estimate of abundance of a rare species (Taylor and Gerrodette 1993). In most wildlife research, the area effectively surveyed is a small fraction, typically $1 \%-10 \%$, of the study area. For the strata covered by the 2008 visual survey (East, Central, and Calibration), the area effectively surveyed was $1,030.6 \times 2 \times 2.12=4,369.7 \mathrm{~km}^{2}$, which was more than $50 \%$ larger than the sum of the stratum areas. In other words, during the 2008 survey each point was sampled more than once on average. The probability of detecting a group of vaquitas at each point in this area was $0.571\left(=\hat{g}_{v}\right)$, which meant that it was probable that some individual vaquitas were sighted more than once. This was simply a consequence of the intensive sampling, and is statistically valid if the transects were random samples. Most of the uncertainty in the total estimates was due to high variance in the encounter rate. The highly clumped nature of vaquita sightings, which has been previously reported (Jaramillo-Legorreta $e t$ al. 1999), makes it difficult to obtain a precise estimate regardless of the amount of survey effort.

\section{Abundance Based on Acoustic Data}

Acoustic methods are increasingly used to contribute information to marine mammal abundance, both to supplement visual line-transect surveys (Barlow and Taylor 2005 ) and to monitor activity and trends directly based on frequency of vocalizations from fixed hydrophones (e.g., Stafford et al. 2001, Carstensen et al. 2006). One of the obstacles to using acoustic data for actual abundance estimation has been that the probability of detecting animals acoustically on the trackline, $g_{a}$, has not been known (Akamatsu et al. 2007). Here, an acoustic trackline detection probability was estimated for the first time for phocoenids as 0.41 . Acoustic detection of vaquitas near the trackline was not certain possibly because (1) vaquitas did not vocalize all the time, (2) the directional high-frequency clicks were not be aimed at the hydrophone and hence not detected, or (3) a combination of these factors.

To combine visual and acoustic data, acoustic survey width $\mathrm{W}_{a}$ was necessary to weight the estimates, as in the Central stratum in this study (Appendix A). For strata in which there was only one kind of data, $\mathbb{W}_{a}$ was not required. Further, the other acoustic line-transect parameters $p_{a}$ and $g_{a}$ did not appear in the estimators of abundance for any strata, since they only occurred as a product probability that a group of vaquitas would be detected acoustically within a strip of width $\mathrm{W}_{a}$. In other words, it was not necessary to estimate $p_{a}$ or $g_{a}$, nor even to measure perpendicular distances to acoustic detections, to estimate vaquita abundance in this study. Nevertheless, we report estimates of $p_{a}, g_{a}$ and acoustic effective strip half-width $\mathrm{ESW}_{a}$ because of their intrinsic interest and conceptual importance. The estimated acoustic ESW for the vaquita in this study $(261 \mathrm{~m})$ was larger than the 
ESW estimated with similar equipment during acoustic surveys for harbor porpoises in the North Sea (208 m, Swift et al. 2006).

In a previous line-transect study, Jaramillo-Legorreta et al. (1999) estimated a "calibration factor" (Appendix A) similar to the present study, although the conversion was expressed in terms of the ratio $f(0) / g(0)$ of the secondary vessel, BIP XI. A direct comparison of the calibration factors in the two studies was that the ratio of detection rates between primary and secondary vessels was 6.8 in 1997 and 11.2 in 2008. Thus, acoustic detections in the present study required a larger factor to estimate abundance than did visual detections in the previous study. This was due partly to the low acoustic trackline detection probability and partly to the better visual conditions in 2008, as already noted.

With one exception, the click trains of each acoustic detection appeared to be from a single individual. Group sizes from visual detections were considerably different, with a mean of 1.9 and only about one-third of sightings being of single animals. These results indicated that either (1) vaquitas in the acoustically surveyed areas rarely occurred in groups, or (2) when the hydrophone passed a group of vaquitas, only one of the animals from the group would usually be detected. Given the directional nature of porpoise clicks, the possibility that calves with mothers vocalized less or not at all, and data indicating incomplete acoustic detection on the trackline, the second explanation seemed more reasonable. We based our acoustic estimates of abundance on the assumption that acoustic detections represented vaquitas of the same mean group size as visual detections.

All abundance estimates based on acoustic data in this study had low precision (CVs $>140 \%$, Table 2). This was due both to the low number of acoustic detections on effort, leading to a high $\mathrm{CV}$ for the encounter rate, and to the low precision of the estimate of $g_{a}$ or, equivalently, the calibration that converted acoustic detections to an estimate of abundance. In the North stratum, for example, a single acoustic detection led to an estimate of 72 vaquitas. The area effectively surveyed acoustically was $170.5 \times 2 \times 0.261 / 1,430.1$ or $6 \%$ of the area. While this fraction was small, it was estimated with reasonable precision $(\mathrm{CV}=21.9 \%$ for the acoustic $\mathrm{ESW})$. Similarly, mean group size was estimated precisely $(\mathrm{CV}=5.1 \%)$. Encounter rate and trackline detection probability, on the other hand, had CVs of $142 \%$ and $108 \%$, respectively. Any future acoustic surveys should strive to estimate $g_{a}$ more precisely, and to increase trackline effort so that estimates of abundance are not based on so few detections.

\section{Implications for Vaquita Conservation}

The present study indicated with high probability that the vaquita population declined between 1997 and 2008. The 2008 population was estimated to be less than half the 1997 population and to consist of only a few hundred animals. Vaquita conservation efforts between 1997 and 2008 were not sufficient to prevent a decline, and the species is in clear danger of extinction. The vaquita conservation action plan (SEMARNAT 2008) has, as its primary goal, the elimination of vaquita bycatch. Under the plan during 2008-2009, approximately one-third of the fishermen were bought out, and enforcement of the ban on gill net fishing in the Refuge Area for the Protection of the Vaquita was greatly increased. Vaquitas move in and out of the Refuge Area, but on average about $50 \%$ of the vaquita population is protected at any moment. Bycatch on the remaining $50 \%$ of the population outside the Refuge Area, however, is likely to cause a further decline in vaquita numbers (Gerrodette and Rojas-Bracho, in press). 
A high scientific priority for vaquita conservation is to improve the ability to monitor changes in abundance. Ship-based surveys are expensive and, due to the imprecision of the estimates, able to detect only large changes after they have already occurred. Current efforts are aimed at developing an array of autonomous acoustic recording devices to monitor vaquita abundance (Rojas-Bracho et al. 2010). Such an acoustic system has the potential to detect changes in vaquita abundance more rapidly and less expensively than the line-transect surveys reported here. If successful, the array of acoustic recorders will provide feedback to managers about whether the conservation plan is working and the vaquita population is recovering, or whether further steps need to be taken to save this porpoise from extinction.

\section{ACKNOWLEDGMENTS}

We would like to thank the funders of the Vaquita Expedition 2008: Instituto Nacional de Ecología of the Secretaría de Medio Ambiente y Recursos Naturales (SEMARNAT), National Marine Fisheries Service of the National Oceanic and Atmospheric Administration (NOAA), the Pacific Life Foundation and the U.S. Marine Mammal Commission, with inkind support from the NOAA Alaska and Northeast Science Centers. We thank the Mexican Navy (SEMAR), Angelica Narvaez (US Embassy), Drs. Adrián Fernández and Eduardo Peters (INE) for their support to all vaquita research; Dr. Martín Vargas (DGVS-SEMARNAT) and José Campoy for helping with the permit process; PROFEPA staff in San Felipe for support; Tim Ragen (MMC) for always supporting our research. Special thanks to Dr. Lisa Ballance for keeping the cruise alive and to Annette Henry and Lynn Evans for cruise logistics support. We are indebted to the officers and crew of NOAA RV David Starr Jordan and the primary team of scientists for the visual survey: Cornelia Oedekoeven, Robert Pitman, Ernesto Vazquez, Dawn Breese, Jay Barlow, Todd Pusser, Anna Hall, Chris Hall, Brenda Rone, BLT, LRB, Sarah Mesnick, Candice Hall, and Tracey Regan. We thank the following scientists for assistance with the acoustic work: Denise Risch, Gustavo Cárdenas, Rodrigo Olson, Steve Brown, Jay Barlow, Nick Trigenza, Aly Fleming, Douglas Gillespie, and Jonathan Gordon. Vaquita Express finances were organized by the Intercultural Center for the Study of Deserts and Oceans (CEDO). The manuscript was substantially improved by the constructive comments of Len Thomas.

\section{Literature Cited}

Akamatsu, T., J. Teilmann, L. A. Miller, et al. 2007. Comparison of echolocation behaviour between coastal and riverine porpoises. Deep-Sea Research II 54:290297.

Anderson, D. R. 2008. Model based inference in the life sciences: A primer on evidence. Springer, New York, NY.

Barlow, J., and B. L. Taylor. 2005. Estimates of sperm whale abundance in the northeastern temperate Pacific from a combined acoustic and visual survey. Marine Mammal Science 21:429-445.

Barlow, J., T. Gerrodette and G. Silber. 1997. First estimates of vaquita abundance. Marine Mammal Science 13:44-58.

Brownell, R. L., Jr. 1986. Distribution of the vaquita, Phocoena sinus, in Mexican waters. Marine Mammal Science 2:299-305.

Buckland, S. T., D. R. Anderson, K. P. Burnham, J. L. Laake, D. L. Borchers and L. Thomas 2001. Introduction to distance sampling: Estimating abundance of biological populations. Oxford University Press, New York, NY.

Camp, R. J., N. E. Seavy, P. M. Gorresen and M. H. Reynolds. 2008. A statistical test to show negligible trend: Comment. Ecology 89:1469-1472. 
Carstensen, J., O. D. Henriksen and J. Teilmann. 2006. Impacts on harbour porpoises from offshore wind farm constuction: Acoustic monitoring of echolocation activity using porpoise detectors (T-PODs). Marine Ecology Progress Series 321:295-308.

Cohen, J. 1994. The earth is round $(p<0.05)$. American Psychologist 49:997-1003.

D’Agrosa, C., C. E. Lennert-Cody and O. Vidal. 2000. Vaquita bycatch in Mexico's artisanal gillnet fisheries: Driving a small population to extinction. Conservation Biology 14:1110-1119.

Dixon, P. M., and J. H. K. Pechmann. 2005. A statistical test to show negligible trend. Ecology 86:1751-1756.

Eguchi, T., and T. Gerrodette. 2009. A Bayesian approach to line-transect analysis for estimating abundance. Ecological Modelling 220:1620-1630.

Fewster, R. M., S. T. Buckland, K. P. Burnham, D. L. Borchers, P. E. Jupp, J. L. Laake and L. Thomas. 2009. Estimating the encounter rate variance in distance sampling. Biometrics 65:225-236.

Gerrodette, T., and L. Rojas-Bracho. 2011. Estimating the success of protected areas for the vaquita, Phocoena sinus. Marine Mammal Science 27:E101-E125.

Gerrodette, T., L. A. Fleischer, H. Pérez-Cortés and B. Villa Ramírez. 1995. Distribution of the vaquita, Phocoena sinus, based on sightings from systematic surveys. International Whaling Commission (Special Issue 16):273-281.

Gillespie, D., and O. Chappell. 2002. An automatic system for detecting and classifying the vocalisations of harbour porpoises. Bioacoustics 13:37-62.

Jaramillo-Legorreta, A. M. 2008. Estatus actual de una especie en peligro de extinción, la vaquita (Phocoena sinus): Una aproximación poblacional con métodos acústicos y bayesianos. Ph.D. thesis, Universidad Autónoma de Baja California. 108 pp.

Jaramillo-Legorreta, A. M., L. Rojas-Bracho and T. Gerrodette. 1999. A new abundance estimate for vaquitas: First step for recovery. Marine Mammal Science 15:957-973.

Jaramillo-Legorreta, A., L. Rojas-Bracho, R. L. Brownell, Jr., A. J. Read, R. R. Reeves, K. Ralls and B. L. Taylor. 2007. Saving the vaquita: Immediate action, not more data. Conservation Biology 21:1653-1655.

Johnson, D. H. 1999. The insignificance of statistical significance testing. Journal of Wildlife Management 63:763-772.

Kinzey, D., and T. Gerrodette. 2001. Conversion factors for binocular reticles. Marine Mammal Science 17:353-361.

Kinzey, D., and T. Gerrodette. 2003. Distance measurements using binoculars from ships at sea: Accuracy, precision and effects of refraction. Journal of Cetacean Research and Management 5:159-171.

Mackenzie, D. I., J. D. Nichols, G. B. Lachman, S. Droege, J. A. Royle and C. A. Langtimm. 2002. Estimating site occupancy rates when detection probabilities are less than one. Ecology 83:2248-2255.

Norris, K. S., and W. N. Mcfarland. 1958. A new harbor porpoise of the genus Phocoena from the Gulf of California. Journal of Mammalogy 39:22-39.

R Development Core Team. 2009. R: A language and environment for statistical computing. R Foundation for Statistical Computing, Vienna, Austria.

Rankin, S., R. Swift, D. Risch, et al. 2009. Vaquita expedition 2008: Preliminary results from a towed hydrophone survey of the vaquita from the Vaquita Express in the upper Gulf of California. NOAA Technical Memorandum, National Marine Fisheries Service, Southwest Fisheries Science Center 439. 38 pp.

Rojas-Bracho, L., A. Jaramillo-Legorreta, G. Cárdenas, et al. 2010. Assessing trends in abundance for vaquita using acoustic monitoring: Within refuge plan and outside refuge research needs. NOAA Technical Memorandum, National Marine Fisheries Service, Southwest Fisheries Science Center 459. 39 pp.

Royle, J. A. 2004. Modeling abundance index data from anuran calling surveys. Conservation Biology 18:1378-1385. 
Satterthwaite, F. E. 1946. An approximate distribution of estimates of variance components. Biometrics Bulletin 2:110-114.

SEMARNAT. 2008. Programa de Acción para la Conservación de la Especie: Vaquita (Phocoena sinus). Estrategia integral para el manejo sustentable de los recursos marinos y costeros en el Alto Golfo de California. Secretaría de Medio Ambiente y Recursos Naturales. 73 pp. Available at http://www.conanp.gob.mx/pdf_especies/PACEvaquita.pdf (accessed 22 August 2008).

Silber, G. K. 1990. Occurrence and distribution of the vaquita Phocoena sinus in the northern Gulf of California. Fishery Bulletin 88:339-346.

Silber, G. K. 1991. Acoustic signals of the vaquita (Phocoena sinus). Aquatic Mammals 17:130133.

Stafford, K. M., S. L. Nieukirk and C. G. Fox. 2001. Geographic and seasonal variation of blue whale calls in the north Pacific. Journal of Cetacean Research and Management 3:65-76.

Swift, R., M. Caillat and D. Gillespie. 2006. Appendix D2.3. Analysis of acoustic data from the SCANS-II survey. Small cetaceans in European Atlantic and North Sea (SCANSII) final report. $18 \mathrm{pp}$. Available at http://biology.st-andrews.ac.uk/scans2/innerfinalReport.html (accessed 31 December 2006).

Taylor, B. L., and T. Gerrodette. 1993. The uses of statistical power in conservation biology: The vaquita and northern spotted owl. Conservation Biology 7:489-500.

Thomas, L., K. P. Burnham and S. T. Buckland. 2004. Temporal inferences from distance sampling surveys. Pages 71-107 in S. T. Buckland, D. R. Anderson, K. P. Burnham, J. L. Laake, D. L. Borchers and L. Thomas, eds. Advanced distance sampling: Estimating abundance of biological populations. Oxford University Press, Oxford, U.K.

Thomas, L., S. T. Buckland, E. A. Rexstad, et al. 2010. Distance software: Design and analysis of distance sampling surveys for estimating population size. Journal of Applied Ecology 47:5-14.

Turvey, S. 2008. Witness to extinction: How we failed to save the Yangtze River dolphin. Oxford University Press, Oxford, UK.

Ver Hoef, J. M., and K. J. Frost. 2003. A Bayesian hierarchical model for monitoring harbor seal changes in Prince William Sound, Alaska. Environmental and Ecological Statistics 10:210-219.

Vidal, O. 1995. Population biology and incidental mortality of the vaquita, Phocoena sinus. Pages 247-272 in A. Bjørge and G. P. Donovan, eds. Biology of the Phocoenids. International Whaling Commission, Cambridge, UK.

Yoccoz, N. G. 1991. Use, overuse, and misuse of significance tests in evolutionary biology and ecology. Bulletin of the Ecological Society of America 72:106-111.

Received: 1 April 2010

Accepted: 25 August 2010

\section{Appendix A}

Abundance in the East stratum $N_{E}$ was estimated from visual data only. From Eq. (1),

$$
\hat{N}_{E}=\left(\frac{\hat{s}}{2 \mathrm{~W}_{v} \hat{p}_{v} \hat{g}_{v}}\right)\left(\frac{n_{v, E}}{\mathrm{~L}_{v, E}}\right) \mathrm{A}_{E},
$$

where the terms have been grouped to aid in interpretation. The first factor contains terms assumed equal across strata. The second factor is the encounter rate (ratio of number of sightings $n$ and kilometers of effort $\mathrm{L}$ ), and is unique to the stratum. The 
product of the first two factors is density (number of animals per unit area), which is multiplied by the area of the stratum to obtain the estimate of abundance. The CV was calculated with the delta method as

$$
\mathrm{CV}^{2}\left(\hat{N}_{E}\right)=\mathrm{CV}^{2}(\hat{s})+\mathrm{CV}^{2}\left(\hat{p}_{v}\right)+\mathrm{CV}^{2}\left(\hat{g}_{v}\right)+\mathrm{CV}^{2}\left(n_{v, E}\right) .
$$

Abundance in the Calibration stratum was estimated from visual data collected during the simultaneous visual and acoustic surveys between 17 and 24 October, as well as during additional transects completed outside this time window (Calibration2). The acoustic data in the Calibration stratum was not used because the acoustic estimate of abundance in this stratum was equal, by design for estimating $g_{a}$, to the visual estimate during the 17-24 October calibration period. The total estimate for the Calibration stratum was the average of the two visual estimates, weighted by the area surveyed during each period.

$$
\begin{aligned}
\hat{N}_{C A L}= & \frac{\mathrm{W}_{v} \mathrm{~L}_{v, \text { Cal }}}{\mathrm{W}_{v} \mathrm{~L}_{v, \text { Cal }}+\mathrm{W}_{v} \mathrm{~L}_{v, \text { Cal } 2}} \cdot \frac{n_{v, \text { Cal }} \hat{s} \mathrm{~A}_{C A L}}{2 \mathrm{~W}_{v} \mathrm{~L}_{v, \text { Cal }} \hat{p}_{v} \hat{g}_{v}} \\
& +\frac{\mathrm{W}_{v} \mathrm{~L}_{v, \text { Cal } 2}}{\mathrm{~W}_{v} \mathrm{~L}_{v, \text { Cal }}+\mathrm{W}_{v} \mathrm{~L}_{v, \text { Cal }}} \cdot \frac{n_{v, \text { Cal } 2} \hat{s} \mathrm{~A}_{C A L}}{2 \mathrm{~W}_{v} \mathrm{~L}_{v, \text { Cal } 2} \hat{p}_{v} \hat{g}_{v}} \\
= & \left(\frac{\hat{s}}{2 \mathrm{~W}_{v} \hat{p}_{v} \hat{g}_{v}}\right)\left(\frac{n_{v, \text { Cal }}+n_{v, \text { Cal } 2}}{\mathrm{~L}_{v, \text { Cal }}+\mathrm{L}_{v, \text { Cal } 2}}\right) \mathrm{A}_{C A L} \\
= & \left(\frac{\hat{s}}{2 \mathrm{~W}_{v} \hat{p}_{v} \hat{g}_{v}}\right)\left(\frac{n_{v, C A L}}{\mathrm{~L}_{v, C A L}}\right) \mathrm{A}_{C A L},
\end{aligned}
$$

where $C a l$ refers to sightings and effort between 17 and 24 October, Cal 2 to sightings and effort outside that period, and $C A L$ to all data in the Calibration stratum. The area-weighted average of the two separate estimates is equal to the estimate based on the total number of sightings and visual effort in the Calibration stratum. The CV was calculated as

$$
\mathrm{CV}^{2}\left(\hat{N}_{C A L}\right)=\mathrm{CV}^{2}(\hat{s})+\mathrm{CV}^{2}\left(\hat{p}_{v}\right)+\mathrm{CV}^{2}\left(\hat{g}_{v}\right)+\mathrm{CV}^{2}\left(n_{v, C A L}\right) .
$$

Abundance in the North and West strata $N_{N}$ and $N_{W}$ was estimated from acoustic data, but depended, through $g_{a}$, on visual and acoustic data in the Calibration stratum. For the North stratum and using Eq. (2),

$$
\begin{aligned}
\hat{N}_{N} & =\left(\frac{\hat{s}}{2 \mathrm{~W}_{a} \hat{p}_{a} \hat{g}_{a}}\right)\left(\frac{n_{a, N}}{\mathrm{~L}_{a, N}}\right) \mathrm{A}_{N} \\
& =\left(\frac{\hat{s}}{2 \mathrm{~W}_{v} \hat{p}_{v} \hat{g}_{v}}\right)\left(\frac{n_{a, N}}{\mathrm{~L}_{a, N}}\right)\left(\frac{n_{v, C a l} \mathrm{~L}_{a, C a l}}{n_{a, C a l} \mathrm{~L}_{v, C a l}}\right) \mathrm{A}_{N},
\end{aligned}
$$

where the third term was a "calibration factor" between visual and acoustic data estimated from the calibration data. The calibration factor was the ratio of encounter rates of the two methods, (visual encounter rate)/(acoustic encounter rate). The CV 
of $\hat{N}_{N}$ was calculated as

$$
\begin{aligned}
\mathrm{CV}^{2}\left(\hat{N}_{N}\right)= & \mathrm{CV}^{2}(\hat{s})+\mathrm{CV}^{2}\left(\hat{p}_{v}\right)+\mathrm{CV}^{2}\left(\hat{g}_{v}\right)+\mathrm{CV}^{2}\left(n_{a, N}\right) \\
& +\mathrm{CV}^{2}\left(n_{v, \text { Cal }}\right)+\mathrm{CV}^{2}\left(n_{a, \text { Cal }}\right),
\end{aligned}
$$

where the last two terms show the additional variance due to estimation of the calibration factor.

Abundance in the Central stratum $N_{C}$ was estimated by a combination of visual and acoustic data, weighted by area surveyed by each method.

$$
\begin{aligned}
\hat{N}_{C} & =\frac{\mathrm{W}_{v} \mathrm{~L}_{v, C}}{\mathrm{~W}_{v} \mathrm{~L}_{v, C}+\mathrm{W}_{a} \mathrm{~L}_{a, C}} \cdot \frac{n_{v, C} \hat{s} \mathrm{~A}_{C}}{2 \mathrm{~W}_{v} \mathrm{~L}_{v, C} \hat{p}_{v} \hat{g}_{v}}+\frac{\mathrm{W}_{a} \mathrm{~L}_{a, C}}{\mathrm{~W}_{v} \mathrm{~L}_{v, C}+\mathrm{W}_{a} \mathrm{~L}_{a, C}} \cdot \frac{n_{a, C} \hat{s} \mathrm{~A}_{C}}{2 \mathrm{~W}_{a} \mathrm{~L}_{a, C} \hat{p}_{a} \hat{g}_{a}} \\
& =\left(\frac{n_{v, C}}{2\left(\mathrm{~W}_{v} \mathrm{~L}_{v, C}+\mathrm{W}_{a} \mathrm{~L}_{a, C}\right)}\right)\left(\frac{n_{a, C}}{\hat{p}_{v} \hat{g}_{v}}\right) \mathrm{A}_{C} \\
& =\left(\frac{\hat{s}}{2 \mathrm{~W}_{v} \hat{p}_{v} \hat{g}_{v}}\right)\left(\frac{\mathrm{W}_{a} n_{a, C}}{\mathrm{~W}_{v} \mathrm{~L}_{v, C}+\mathrm{W}_{a} \mathrm{~L}_{a, C}}\right)\left(\frac{n_{v, C a l} \mathrm{~L}_{a, C a l}}{n_{a, C a l} \mathrm{~L}_{v, C a l}}\right) \mathrm{A}_{C},
\end{aligned}
$$

because, as it turned out, $n_{v, C}=0$ (see Results). The squared CV of this estimator was

$$
\begin{aligned}
\mathrm{CV}^{2}\left(\hat{N}_{C}\right)= & \mathrm{CV}^{2}(\hat{s})+\mathrm{CV}^{2}\left(\hat{p}_{v}\right)+\mathrm{CV}^{2}\left(\hat{g}_{v}\right)+\mathrm{CV}^{2}\left(n_{a, C}\right) \\
& +\mathrm{CV}^{2}\left(n_{v, \text { Cal }}\right)+\mathrm{CV}^{2}\left(n_{a, C a l}\right)
\end{aligned}
$$

where again the last two terms show the additional variance due to estimation of the calibration factor for the acoustic data.

\section{APPENDIX B}

Total vaquita abundance was estimated as the sum of the stratum estimators

$$
\hat{N}_{t o t}=\hat{N}_{E}+\hat{N}_{C A L}+\hat{N}_{N}+\hat{N}_{C}+\hat{N}_{W}
$$

There were no vaquita detections in the West stratum, so $\hat{N}_{W}=0$. Using the stratum estimators in Appendix A and factoring out common terms so that each random variable appears only once, we may express the total estimator as

$$
\begin{aligned}
\hat{N}_{t o t}= & \left(\frac{\hat{s}}{2 \mathrm{~W}_{v} \hat{p}_{v} \hat{g}_{v}}\right)\left\{\frac{\mathrm{A}_{E}}{\mathrm{~L}_{v, E}} n_{v, E}+\frac{\mathrm{A}_{C A L}}{\mathrm{~L}_{C A L}} n_{v, C a l 2}+\left[\frac{\mathrm{A}_{C A L}}{\mathrm{~L}_{C A L}}+\left(\frac{\mathrm{A}_{N} \mathrm{~L}_{a, C a l}}{\mathrm{~L}_{a, N} \mathrm{~L}_{v, C a l}} n_{a, N}\right.\right.\right. \\
& \left.\left.\left.+\frac{\mathrm{A}_{C} \mathrm{~W}_{a} \mathrm{~L}_{a, C a l}}{\left(\mathrm{~W}_{v} \mathrm{~L}_{v, C}+\mathrm{W}_{a} \mathrm{~L}_{a, C}\right) \mathrm{L}_{v, \text { Cal }}} n_{a, C}\right) \frac{1}{n_{a, C a l}}\right] n_{v, \text { Cal }}\right\} .
\end{aligned}
$$


Letting

$$
\begin{aligned}
\mathrm{F}_{E} & =\frac{\mathrm{A}_{E}}{\mathrm{~L}_{v, E}}, \\
\mathrm{~F}_{C A L} & =\frac{\mathrm{A}_{C A L}}{\mathrm{~L}_{v, C A L}}, \\
\mathrm{~F}_{N} & =\frac{\mathrm{A}_{N} \mathrm{~L}_{a, C a l}}{\mathrm{~L}_{a, N} \mathrm{~L}_{v, C a l}} \\
\mathrm{~F}_{C} & =\frac{\mathrm{A}_{C} \mathrm{~W}_{a} \mathrm{~L}_{a, C a l}}{\left(\mathrm{~W}_{v} \mathrm{~L}_{v, C}+\mathrm{W}_{a} \mathrm{~L}_{a, C}\right) \mathrm{L}_{v, C a l}} \\
Q & =\mathrm{F}_{N} n_{a, N}+\mathrm{F}_{C} n_{a, C}, \\
R & =\mathrm{F}_{C A L}+Q \frac{1}{n_{a, C a l}}, \\
T & =\mathrm{F}_{E} n_{v, E}+\mathrm{F}_{C A L} n_{v, C a l 2}+R n_{v, \text { Cal }},
\end{aligned}
$$

and using the identities

$$
\mathrm{CV}^{2}(x y)=(x y)^{-2}\left[y^{2} \operatorname{var}(x)+x^{2} \operatorname{var}(y)\right]=\mathrm{CV}^{2}(x)+\mathrm{CV}^{2}(y)
$$

and

$$
\mathrm{CV}^{2}(x+y)=(x+y)^{-2}[\operatorname{var}(x)+\operatorname{var}(y)]
$$

with the delta method when random variables $x$ and $y$ are independent, the squared coefficient of variation of the total estimator was

$$
\begin{aligned}
\mathrm{CV}^{2}\left(\hat{N}_{t o t}\right)= & \mathrm{CV}^{2}(\hat{s})+\mathrm{CV}^{2}\left(\hat{p}_{v}\right)+\mathrm{CV}^{2}\left(\hat{g}_{v}\right)+T^{-2}\left\{\mathrm{~F}_{E}^{2} \operatorname{var}\left(n_{v, E}\right)+\mathrm{F}_{C A L}^{2} \operatorname{var}\left(n_{v, C a l 2}\right)\right. \\
& +\left(n_{v, C a l} R\right)^{2}\left[\mathrm{CV}^{2}\left(n_{v, C a l}\right)+\mathrm{CV}^{2}\left(n_{a, C a l}\right)\right. \\
& \left.\left.+Q^{-2}\left(\mathrm{~F}_{N}^{2} \operatorname{var}\left(n_{a, N}\right)+\mathrm{F}_{C}^{2} \operatorname{var}\left(n_{a, C}\right)\right)\right]\right\} .
\end{aligned}
$$

\section{ApPENDIX C}

A significance test of the difference between the 1997 and 2008 vaquita abundance estimates was based on

$$
t^{\prime}=\frac{\hat{d}}{\hat{s}_{\hat{d}}}=\frac{\hat{N}_{1997}-\hat{N}_{2008}}{\sqrt{\operatorname{var}\left(\hat{N}_{1997}\right)+\operatorname{var}\left(\hat{N}_{2008}\right)}}
$$

with reference to Student's $t$ distribution. The calculation of the standard deviation $\hat{s}_{\hat{d}}$ assumed that the 1997 and 2008 estimates were independent. Although most of the data were collected independently in the $2 \mathrm{yr}$, the estimation of $N_{2008}$ from visual 
data used an estimate of visual trackline detection probability from data collected in 1997. This induced a slight positive correlation between the estimates of $N_{1997}$ and $N_{2008}$. In the equation above, therefore, $\hat{s} \hat{d}$ was underestimated, which meant that $t^{\prime}$, and the $P$ value calculated from it, were too low. In other words, if the positive correlation between the estimates of $N_{1997}$ and $N_{2008}$ were accounted for, the $P$ values computed below would be slightly higher.

For estimates of total abundance and their variances, we used the results in Table 1 of Jaramillo-Legorreta et al. (1999) and Table 2 of this paper. For estimates of abundance in the central area, we used the modes and variances of the posterior distributions of $N_{1997}$ and $N_{2008}$ from the Bayesian line-transect analysis reported in this paper. These gave values of $t^{\prime}=1.00$ for estimates of total abundance and $t^{\prime}=$ 0.97 for estimates of abundance in the central area.

The degrees of freedom for these $t$ statistics were not clearly defined because variances were estimated by complicated processes. The least conservative assumption was that variances were known, not estimated, which is equivalent to a Wald test, in which case

$$
P\left(t^{\prime} \geq t_{0.05(2), \infty}\right)=0.315
$$

for a two-tailed test at the $\alpha=0.05$ significance level for the total estimates, and

$$
P\left(t^{\prime} \geq t_{0.05(2), \infty}\right)=0.333
$$

for the estimates in the central area. Alternatively, the degrees of freedom could be approximated by (Satterthwaite 1946)

$$
v=\frac{\left[\operatorname{var}\left(\hat{N}_{1997}\right)+\operatorname{var}\left(\hat{N}_{2008}\right)\right]^{2}}{\frac{\left[\operatorname{var}\left(\hat{N}_{1997}\right)\right]^{2}}{n_{1997}-1}+\frac{\left[\operatorname{var}\left(\hat{N}_{2008}\right)\right]^{2}}{n_{2008}-1}} \cong 19,
$$

where $n_{1997}=11$ and $n_{2008}=17$ were the number of visual transects in each year. Then for the total estimates,

$$
P\left(t^{\prime} \geq t_{0.05(2), 19}\right)=0.328
$$

and for the central area estimates,

$$
P\left(t^{\prime} \geq t_{0.05(2), 19}\right)=0.345 \text {. }
$$

Fewer degrees of freedom, or accounting for the slight positive correlation between the estimates of $N_{1997}$ and $N_{2008}$, would give larger $P$ values in both cases. 